\section{Aspectos bioéticos envolvidos no transplante renal com doadores vivos não relacionados}

Neres, RML

Curso de Medicina do Centro Universitário de Brasília

(UniCEUB).E-mail: rebeka.neres@gmail.com

\section{Sousa, FF}

Curso de Medicina do Centro Universitário de Brasília (UniCEUB).

\section{Ribeiro, LMN}

Curso de Medicina do Centro Universitário de Brasília (UniCEUB).

\section{Botelho, ALT}

Curso de Medicina do Centro Universitário de Brasília (UniCEUB).

\section{Ferraz, FHRP}

Programa de Pós-graduação em Bioética - Universidade de Brasília. Professor Adjunto de Medicina do Centro Universitário de Brasília (Uniceub)

PALAVRAS-CHAVE: Transplante Renal, Doação, Doadores de Órgãos, Ética, Bioética

Introdução: A doença renal crônica dialítica é considerada um problema de saúde pública devido a sua crescente prevalência e ao elevado impacto econômico para manutenção dos pacientes nas diversas formas de terapias existentes ( sobretudo diálise e transplante renal ). Em vista da assimetria entre pacientes com falência renal terminal e a demanda de órgãos viáveis para transplante, o debate sobre flexibilização ou mesmo estímulo a doação de rins entre indivíduos não relacionados ressurgiu na literatura. O Brasil é um dos países de destaque no cenário internacional, sendo o segundo maior em número bruto de transplantes renais / ano, mais de 95\% custeados pelo Sistema Único de Saúde ( SUS). O transplante de doadores vivos não relacionados só é permitido após trâmite judicial, com vistas a coibir o tráfico de órgãos. Neste contexto, este trabalho objetiva analisar artigos nacionais visando identificar aspectos bioéticos relacionados ao transplante renal intervivos entre indivíduos não relacionados. Metodologia: Trata-se de uma revisão integrativa sobre bioética e transplante renal intervivos na literatura nacional . A busca realizada nas bases de dados Google Acadêmico, LILACS, PubMed/ Medline e Scielo com delimitação temporal dos últimos 15 anos (2002-2017). Os descritores utilizados foram: bioética, transplante renal , transplante renal não relacionado, ética médica e Brasil, com os respectivos descritores em inglês . Critérios de exclusão: inadequação ao tema, não-artigos ( teses ou dissertações), artigos repetidos, artigos não-nacionais. Ao final, foram selecionados 11 artigos nacionais que constituíram a análise deste estudo . Resultados: Dos 10 artigos, 6 englobavam revisões de literatura , 3 eram estudos transversais e um uma revisão integrativa.. Cerca de quatro expunham os potenciais riscos de descumprimento dos princípios bioéticos no processo de doação de órgãos, além do questionamento da eficácia da legislação em coibir o tráfico de órgãos. Entretanto, um artigo questionou a possibilidade de flexibilização da lei, em vista das mudanças na estrutura familiar brasileira, como a existência de casais homoafetivos, uniões mútuas de concubinato não legalizadas, dentre outras. Conclusão: As questões envolvendo a flexibilização do transplante renal intervivos são complexas, havendo argumentos a favor da mesma. Entretanto, em um contexto social de importantes disparidades econômicas e sociais como no caso do Brasil, a desigualdade social não permite um pleno exercício da autonomia na população mais vulnerável econômica e socialmente. Nestes casos, o "princípio" bioético da prudência talvez seja o mais importante, na medida em que a manutenção da legislação atual respeita a noção kantiana de dignidade humana, limitando a possibilidade de transplantes intervivos entre não relacionados como forma de coibir o "comércio" de órgãos.

AGRADECIMENTOS: Agradecemos à instituição UniCEUB. À Liga Acadêmica de Nefrologia do UniCEUB (LANEFRU).

\section{REFERÊNCIAS}

[1] FERREIRA GF, GUEDES CD. Living unrelated kidney donors: ethical aspects of living kidney donation in Brazil. Indian Journal of Medical Ethics 2011, 8(2):112-4

[2] MUELLER, Paul S.; CASE, Ellen J.; HOOK, C. Christopher. Responding to offers of altruistic living unrelated kidney donation by group associations: an ethical analysis. Transplantation Reviews, v. 22, n. 3, p. 200-205, 2008.

[3] PASSARINHO, Lúcia Eugênia Velloso; GONÇALVES, Mauro Pedroso; GARRAFA, Volnei. Estudo bioético dos transplantes renais com doadores vivos não-parentes no Brasil: a ineficácia da legislação no impedimento do comércio de órgãos. Rev Assoc Med Bras, v. 49, n. 4, p. 382-8, 2003.

[4] ALMEIDA, E. C. de; BUENO, S. M. V.; DONOSO, L. M. B.; REIS, L. N. dos; VIEIRA, T. R. Aspectos ético-legais envolvidos no processo de doação/transplante. Arq. Ciênc. Saúde UNIPAR, Umuarama, v. 16, n. 3, p. 105-109, set./dez. 2012.

[5] FERREIRA, Isabelle R.; et al. Doação e transplante de órgãos na concepção bioética: uma revisão integrativa. Rev. Universidade Vale do Rio Verde, Três Corações, v.13, n. 1, p. $190-203,2015$ 